\title{
Host Preference and Seedborne Transmission of Ditylenchus weischeri and $D$. dipsaci on Select Pulse and Non-Pulse Crops Grown in the Canadian Prairies
}

\author{
Abolfazl Hajihassani and Mario Tenuta, Department of Soil Science, and Robert H. Gulden, Department of Plant Science, University of \\ Manitoba, Winnipeg, MB, R3T 2N2 Canada
}

\begin{abstract}
Hajihassani, A., Tenuta, M., and Gulden, R. H. 2016. Host preference and seedborne transmission of Ditylenchus weischeri and D. dipsaci on select pulse and non-pulse crops grown in the Canadian Prairies. Plant Dis. 100:1087-1092.

The stem nematode Ditylenchus weischeri was recently reported on creeping thistle (Cirsium arvense) in Canada. Two greenhouse studies examined host suitability of crops commonly grown in the Canadian Prairies for $D$. weischeri and the closely related parasite of many crops, $D$. dipsaci. In the first study, common pulse crops (yellow pea, chickpea, common bean, and lentil), spring wheat, canola, creeping thistle, and garlic were evaluated. Plant biomass and reproductive factor $\left(\mathrm{R}_{\mathrm{f}}=\right.$ nematode recovered/inoculated $) 8$ weeks postinoculation were used to determine host suitability. Creeping thistle biomass was reduced by $D$. weischeri whereas $D$. dipsaci reduced biomass of

four of five pea and two of three bean varieties. Two pea varieties were weak hosts for $D$. weischeri, with $\mathrm{R}_{\mathrm{f}}$ slightly $>1$. D. weischeri aggressively reproduced on creeping thistle $\left(\mathrm{R}_{\mathrm{f}}=5.4\right)$. D. dipsaci reproduced aggressively on garlic $\left(R_{f}=6.4\right.$; a known host), moderately on pea varieties $\left(R_{f}>2\right)$, and weakly on chickpea and bean $\left(\mathrm{R}_{\mathrm{f}}>1\right)$. In the second study, using creeping thistle and yellow pea, $D$. weischeri was recovered from aboveground parts of the plants and seed of the former and $D$. dipsaci from the later. The results show that $D$. weischeri parasitizes creeping thistle but not other crops and that $D$. weischeri host preference is different from that of $D$. dipsaci.
\end{abstract}

Cool-season pulse and non-pulse crops can be parasitized by some plant-parasitic nematodes of the genus Ditylenchus (Sikora and Greco 1990; Stoddard et al. 2010). Among the many species in the genus, Ditylenchus dipsaci, D. destructor, D. gigas, D. angustus, D. africanus, and $D$. arachis are major pests of crops such as potato (Solanum tuberosum), broad bean (Vicia faba), pea (Pisum sativum), common bean (Phaseolus vulgaris), lucerne (Medicago sativa), onion (Allium cepa), garlic (A. sativum), rice (Oryza sativa), and peanut (Arachis hypogaea), while the majority of species feed on some soil fungi (Plowright et al. 2002; Sturhan and Brzeski 1991; Vovlas et al. 2011; Zhang et al. 2014).

The stem and bulb nematode D. dipsaci (Kühn) Filipjev is almost globally distributed, with significant potential to reduce production of many crops. It is an obligate parasite that feeds and reproduces in the parenchymatous tissues of 450 to 500 plant species, causing the middle lamellae of cell walls to break down (Bridge and Starr 2007; Sturhan and Brzeski 1991). This nematode has been the subject of external quarantine regulations of many countries and almost all countries have strict quarantine regulations to prevent the probability of its importation through infested soil, seed, and plant materials. Both the above- and belowground parts of host plants are infested by the nematode (CABI 2015; Plowright et al. 2002).

In Canada, the occurrence and prevalence of $D$. dipsaci has been confined to garlic, alfalfa, onion, and carrot crops in Alberta, British Columbia, Ontario, Quebec, and Prince Edward Island (Fushtey and Kelly 1975; Hawn 1963; Mountain 1957; Vrain and Lalik 1983; Yu et al. 2010). Watson and Shorthouse (1979) reported D. dipsaci infesting creeping thistle (Cirsium arvense) near Regina, Saskatchewan. However, Chizhov et al. (2010) described a new species, D. weischeri, on creeping thistle in Russia based on morphological and polymerase chain reaction restriction fragment length polymorphism analysis. Recently, we reported $D$. weischeri and not $D$. dipsaci commonly associated with creeping thistle in Saskatchewan and Manitoba (Tenuta et al. 2014). Species-specific primers have been developed to quickly differentiate

Corresponding author: M. Tenuta; E-mail: mario.tenuta@umanitoba.ca

Accepted for publication 25 January 2016.

http://dx.doi.org/10.1094/PDIS-11-15-1260-RE

(C) 2016 The American Phytopathological Society
D. weischeri and D. dipsaci (Madani et al. 2015). D. weischeri has been found on creeping thistle and is believed not to parasitize crops; however, only onion and strawberry have been examined (Chizhov et al. 2010).

Various procedures for determining the host suitability of plantparasitic nematodes have been used previously. The most common approach is the reproductive factor $\left(\mathrm{R}_{\mathrm{f}}\right)$ value: the ratio of recovered to added nematode numbers. In some host-suitability studies, the comparison between a reference host of known $R_{f}$ value and the $R_{f}$ value of the test host was used (Inomoto and Asmus 2010; Vanstone and Russ 2001). Other studies have used assessment of host suitability of test plants as nonhost $\left(\mathrm{R}_{\mathrm{f}}<1\right.$, nematode penetrates into plant with no reproduction occurs), poor host $\left(\mathrm{R}_{\mathrm{f}}=1\right.$, little reproduction or nematode survival occurs), and increasing host suitability, with $\mathrm{R}_{\mathrm{f}}$ divided into qualitative categories such as intermediate host (medium increase in the number of nematode occurs) and good or excellent host (large increase in the number of nematode occurs) (Forge et al. 2012; MacGuidwin et al. 1992).

Although $D$. weischeri is presently known as a highly specialized stem nematode parasitizing only Cirsium spp. in the Canadian Prairies, there is a lack of knowledge about host preference of this nematode species to commonly grown pulse and non-pulse crops in the Canadian Prairies, and whether it can be transmitted by infected seed of the crops. Therefore, the objectives of this study were to (i) assess the host status of four pulse and two non-pulse crops for D. weischeri and D. dipsaci; (ii) evaluate the reproduction capacity of these nematodes on different varieties of yellow pea, common, bean and chickpea; and (iii) determine whether these nematodes are seedborne transmissible in yellow pea and creeping thistle.

\section{Material and Methods}

Preparation of Ditylenchus spp. inoculum. A D. weischeri population was obtained from an infected creeping thistle plant collected at the University of Manitoba Glenlea Research Station, Glenlea, Manitoba, Canada. Additionally, a population of D. dipsaci from Ontario, isolated from infected garlic, was obtained. To prepare nematode inoculum, $D$. weischeri and $D$. dipsaci fourth-stage juveniles (J4) were reared on creeping thistle and garlic plants, respectively. Four creeping thistle rhizomes and garlic cloves (artichoke garlic), were planted in 24-cm-diameter polyethylene pots filled with a nematode-free clay-sand-peat mix $(1: 1: 2, \mathrm{vol} / \mathrm{vol})$. Young plants were inoculated by pipetting approximately $2,000 \mathrm{~J} 4$ into three holes 
around each shoot. The plants were covered with transparent polyethylene bags and then grown for 3 to 4 months in a growth chamber at $23 \pm 2{ }^{\circ} \mathrm{C}$, with a 14 -h photoperiod of fluorescent light. Active nematodes were extracted using a Whitehead tray method (Whitehead and Hemming 1965) from the infested plants and stored in water at $4^{\circ} \mathrm{C}$ until use.

Host preference study. Two experiments were conducted in a greenhouse from November 2012 to February 2014 to examine the host suitability of pulse and non-pulse crops to D. weischeri and D. dipsaci and to assess the reproduction variability of these nematodes on yellow pea, common bean, and chickpea varieties. Seed of yellow pea (Pisum sativum) vars. Agassiz, Admiral, Meadow, Golden, and Bronco chickpea (Cicer arietinum) vars. CDC Corinne (Desi) and CDC Frontier (Kabuli); large green seed lentil (Lens culinaris) var. CDC Greenland; common bean (Phaseolus vulgaris) vars. Windbreaker (pinto), Pink panther (kidney), and Envoy (navy); spring wheat (Triticum aestivum) var. AC Barrie; and canola (Brassica napus) var. Invigor were planted (one per pot) to 12-cm-diameter polyethylene pots containing the same soil mixture as described previously. Prior to inoculation, the nematode suspension was microscopically examined to confirm that all nematode individuals were J4. Suspensions of approximately 5,000 J4 were transferred to a glass centrifuge tube and concentrated at $1,500 \times g$ for 3 to $4 \mathrm{~min}$. Then, the supernatant was removed and replaced with $1.5 \%$ carboxymethyl cellulose (CMC; Sigma-Aldrich, St Louis). CMC was added to the nematode suspension to reduce nematode death due to drying on the leaf axil surface and to increase potential of penetration of J4 individuals into the seedlings. The nematode inoculum was adjusted to 5,000 fresh individuals per $1.5 \mathrm{ml}$ and $15 \mu \mathrm{l}$ containing $50 \mathrm{~J} 4$ pipetted onto leaf axils of seedlings at the second true-leaf stage (except for garlic, which was inoculated at first-leaf stage), and then again 5 days later. Therefore, the total number of nematodes inoculated was $100 \mathrm{~J} 4$ per plant. Plants inoculated with CMC alone (no nematode) were used as a negative control. In addition to the negative control, in each trial, a positive host control was included by inoculating creeping thistle and garlic, grown in 12-cm-diameter polyethylene pots, with $D$. weischeri and $D$. dipsaci, respectively. Because high humidity is required to favor nematode penetration and infestation under greenhouse conditions and also to increase relative humidity (approximately 80 to 90\%) and prevent inoculum droplets from drying quickly, plants were incubated for a total of 6 days in a chamber comprising a translucent plastic canopy and external humidifier (Herrmidifier 707U, Effingham, IL), introducing water vapor to the former via a PVC pipe. Relative humidity in the chamber was not determined. However, condensation was avoided to prevent washing added nematodes off seedlings by using the PVC pipe with perforation to introduce humidified air into the chamber.

Thereafter, the pots were placed on two benches in a greenhouse at $25 \pm 2^{\circ} \mathrm{C}$ and watered every other day. Because of the risk of crosscontamination, the treated plants were not placed directly beside the control plants; however, treatment and control plants for each nematode species were placed on two separate benches with inoculated treatment groups (nine plants of a single plant or variety) separated from other groups by polyethylene sheets. Control and treatment groups (nine plants within each) were randomized on the bench. Therefore, individual pots served as pseudoreplicates or subsamples and the two repeats of the experiment were considered the true replicates.

The treated plants were grown for 8 weeks prior to extraction of nematodes. At 8 weeks, each plant was cut off at the soil surface and the fresh weight of aboveground biomass was recorded. The leaves of the seedling were detached from stems and the stems split in half. Then, the leaves and stems were cut into small segments of 0.5 to $1 \mathrm{~cm}$ in length and nematodes were extracted for 3 days using the Whitehead tray method. In a previous test (unpublished data), we determined that $99 \%$ of added D. weischeri and D. dipsaci where recovered 3 days after inoculation. If there was more than $15 \mathrm{~g}$ fresh weight of plant material in a pot, the material in excess of $15 \mathrm{~g}$ was extracted using a another tray. The trays (18 cm in diameter) were plastic, containing one layer of paper towel on a wire mesh $(700-\mu \mathrm{m}$ screen size) supported by 3 -mm-thick plastic rings. Tap water was added to the trays to just cover the plant material on the paper towel. After nematode extraction, the volume of the nematode suspension obtained from each plant was concentrated to $3 \mathrm{ml}$ by centrifugation; then, the population density of the nematodes was enumerated under a microscope using a counting slide. The $\mathrm{R}_{\mathrm{f}}$ of the nematodes was determined by dividing the total number of nematodes recovered from a plant by the initial number of nematodes added (100 J4). In this study, we categorized $\mathrm{R}_{\mathrm{f}}$ as $<1=$ nonhost, 1 to $2=$ poor host, 2 to $4=$ good host, and $>4=$ excellent host.

Seedborne transmission study. This study was conducted twice during February to May 2014 to determine feeding or reproduction location preference of $D$. weischeri and $D$. dipsaci within belowand aboveground parts of yellow pea and creeping thistle plants, including roots, stems, leaves, seed pods, flower heads, and seed. Seed of Agassiz yellow pea and segmented rhizomes of creeping thistle were germinated after surface sterilization with sodium hypochlorite (5\%) on damp filter paper to produce sprouts. To supply sufficient inoculum of $D$. weischeri and D. dipsaci, the nematodes were reared on carrot callus cultures (unpublished data). For this culturing method, $D$. weischeri and D. dipsaci were isolated from creeping thistle and garlic stems, respectively, and placed in streptomycin sulfate suspension $(4,000 \mathrm{mg} /$ liter; Sigma-Aldrich) overnight, then washed several times in sterile distilled water. Individuals of each nematode species were then pipetted onto surface-sterilized carrot disks and incubated in the dark at $23^{\circ} \mathrm{C}$.

As soon as emergence of coleoptile, one pregerminated seed of yellow pea or rhizome of creeping thistle was sown in each pot and inoculated with 1,000 mixed life stages (86\% juveniles and $14 \%$ adults) of either D. weischeri or D. dipsaci in $20 \mu \mathrm{l}$ of a $1.5 \%$ $\mathrm{CMC}$ suspension. The difference in nematode life stage used in the transmission study compared with the host preference study (only J4) was due to using nematodes recovered from carrot disk cultures rather than from creeping thistle and garlic plants. Each pot was considered a replication and treatments were set on a bench in greenhouse. The design of the experiment was similar to the host preference study, with six replications (pots) per plant species. Inoculated plants were checked carefully during the tests to record any symptoms of disease or injury by the nematode species.

Plants infested by $D$. weischeri and $D$. dipsaci were harvested when yellowing and senescence of plants occurred, about 67 to 69 days after emergence. Extraction of nematodes from roots, stems, leaves, seed pods, flower heads, and seed was done as described previously. The roots were cut at the point of attachment to the base of the stems and washed free of soil. The leaves were first detached from the stems; then, each plant stem was separated into two parts (bottom and top). With regard to pea seed, seed coats were removed and nematodes were extracted from the germ portion (hypocotyl and radicle) and storage cotyledons by soaking for $48 \mathrm{~h}$ in tap water. The total number of the nematodes recovered from each plant part was determined as described previously.

Statistical analysis. A mixed-model analysis of variance (ANOVA) was used to analyze nematode recovery data generated in the host preference and transmission studies. Prior to each analysis, the assumptions for normality of residuals was tested and corrected when necessary. To meet the assumption of normality, response variable data were $\log _{10}$ transformed when necessary and inspected for outliers. For the host preference study, host species or variety was considered the fixed effect while experimental repeat (the true replicate) and plant repeat (the pseudoreplicate) were considered random effects. The pseudoreplicate (plant) was nested within the true replicate (experiment). Due to the unbalanced nature of plant species and varieties, the ANOVA was conducted using a one-way treatment structure.

All tests were conducted at $\alpha=0.05$. When necessary, heterogeneity of variance was corrected by using the Repeated/Group statement in Proc Mixed. Means comparison of the nematode $R_{f}$ in the host preference study and recovered number of nematodes in the seedborne transmission study was done using Tukey's honestly significant difference test and the pdmix 800 macro (Saxton 1998). Individual least-squares means (LSmeans) $t$ tests indicating whether the mean was significantly different from zero were used to determine whether the nematode $\mathrm{R}_{\mathrm{f}}$ was different from 1 ; the base 10 logarithm of 1 is 
zero. Thus, individual $t$ tests that showed that the treatment mean was significantly different from 0 indicated that the $\mathrm{R}_{\mathrm{f}}$ deviated significantly from 1 .

To determine whether the nematodes affected plant aboveground biomass in the host preference study, a one-way ANOVA using the same model as for the $\mathrm{R}_{\mathrm{f}}$ response variable was conducted. For this analysis, biomass of a plant species inoculated with a species of nematode was expressed as a ratio of the average of all noninoculated plants of the same species. The ratio data were then log-transformed to meet the assumption of ANOVA. The log-transformation also allowed for testing which of these values were significantly different from their respective noninoculated controls by using the LSmeans $t$ test that determines when a mean is different from 0 (similar to the $t$ test used above for nematode $\mathrm{R}_{\mathrm{f}}$ ).

A similar mixed-model approach was used to examine the data (nematode count) from the transmission study. A separate one-way ANOVA was conducted for each plant and nematode species combination. Plant organ was considered the fixed effect while experimental repeat and plant within experimental repeat were considered random effects. Assumption testing and means separation were conducted as outlined above. All statistical analyses were done using SAS (v. 9.3; SAS Institute, Cary, NC).

\section{Results}

Host preference of $D$. weischeri and $D$. dipsaci. D. weischeri reproduced best on creeping thistle, with this plant being the most preferred host of the plant species examined here, having a significantly higher $R_{\mathrm{f}}$ than that for other plant species and varieties examined (Fig. 1). The $\mathrm{R}_{\mathrm{f}}$ of $D$. weischeri on yellow pea Agassiz, Golden, Meadow, and Admiral was $>1$. Bronco had an Rf value $<1$ (Fig. 1). However, our statistical analysis showed that the nematode $R_{f}$ of Meadow, Admiral, and Bronco was not different than 1 . The $\mathrm{R}_{\mathrm{f}}$ of D. weischeri was slightly greater than $1\left(\mathrm{R}_{\mathrm{f}}=1.17, P<0.0001\right)$ when data across all five yellow pea varieties were pooled over the two experiments.

The other pulse and non-pulse crops tested (lentil, chickpea, common bean, spring wheat, canola, and garlic) had $\mathrm{R}_{\mathrm{f}}$ values $<1(P<$ 0.05 ; Fig. 1) for $D$. weischeri. At 8 weeks after nematode inoculation and compared with the noninoculated control, D. weischeri did not affect aboveground biomass of any of the plants evaluated except creeping thistle (Table 1). Acid fuchsin-stained eggs, juveniles, and adults of $D$. weischeri were observed in the stem of creeping thistle
(Fig. 2A). In the current study, symptoms of the nematode injury on creeping thistle were chlorosis, slight swelling of stems, and twisting and malformation of leaves.

Among the hosts examined in our study, garlic was most preferred by $D$. dipsaci, with an $\mathrm{R}_{\mathrm{f}}$ value $>6$ (Fig. 3). Yellow pea was also an excellent host for $D$. dipsaci, with $\mathrm{R}_{\mathrm{f}}$ values ranging from 2.3 to 6.9 among varieties tested (Fig. 3). Our results indicated that the nematode reproduction varied among yellow pea varieties (Fig. 3). Among yellow pea varieties tested, Bronco was less susceptible to $D$. dipsaci, followed by Admiral, Agassiz, Golden, and Meadow, in which the nematode reproduced aggressively. Under the experimental conditions, chickpea vars. CDC Corinne (desi) and CDC Frontier (Kabuli) and common bean Windbreaker (pinto), Pink panther (kidney), and Envoy (navy) were rated as poor to good hosts for $D$. dipsaci $\left(\mathrm{R}_{\mathrm{f}}>1\right)$.

Table 1. Percentage reduction of the control in aboveground biomass of pulse and non-pulse crops with inoculation of Ditylenchus weischeri and D. dipsaci and biomass of corresponding uninoculated controls

\begin{tabular}{lccc}
\hline & \multicolumn{2}{c}{$\begin{array}{c}\text { Biomass of treated } \\
\text { plants (\% of } \\
\text { control plants) }\end{array}$} & \\
\cline { 2 - 3 } Plant & $\begin{array}{c}\text { D. } \text { weischeri } \\
\text { D. dipsaci }\end{array}$ & $\begin{array}{c}\text { Control } \\
\text { (g FW/plant) }\end{array}$ \\
\hline Creeping thistle & $84^{*}$ & 94 & 13.9 \\
Wheat (var. Barrie) & 96 & 84 & 9.1 \\
Canola (var. Invigor) & 90 & 84 & 17.4 \\
Garlic & 92 & 85 & 19.8 \\
Chickpea (var. CDC Corinne) & 88 & 97 & 9.2 \\
Chickpea (var. CDC Frontier) & 100 & 78 & 11.3 \\
Lentil (var. CDC Greenland) & 77 & 76 & 3.1 \\
Yellow pea (var. Agassiz) & 92 & 88 & 16.4 \\
Yellow pea (var. Admiral) & 90 & $78^{*}$ & 13.7 \\
Yellow pea (var. Meadow) & 82 & $73^{*}$ & 14.1 \\
Yellow pea (var. Golden) & 90 & $78^{*}$ & 16.1 \\
Yellow pea (var. Bronco) & 93 & $85^{*}$ & 17.5 \\
Bean (var. Pink panther) & 102 & 82 & 23.4 \\
Bean (var. Windbreaker) & 92 & $87^{*}$ & 24.6 \\
Bean (var. Envoy) & 87 & $86^{*}$ & 23.8 \\
\hline
\end{tabular}

y Asterisks indicate which treatments had significantly $(P<0.05)$ lower aboveground biomass weight according to Tukey's honestly significant difference test compared with the control.

${ }^{\mathrm{z}}$ Biomass of control plants; $\mathrm{FW}=$ fresh weight.

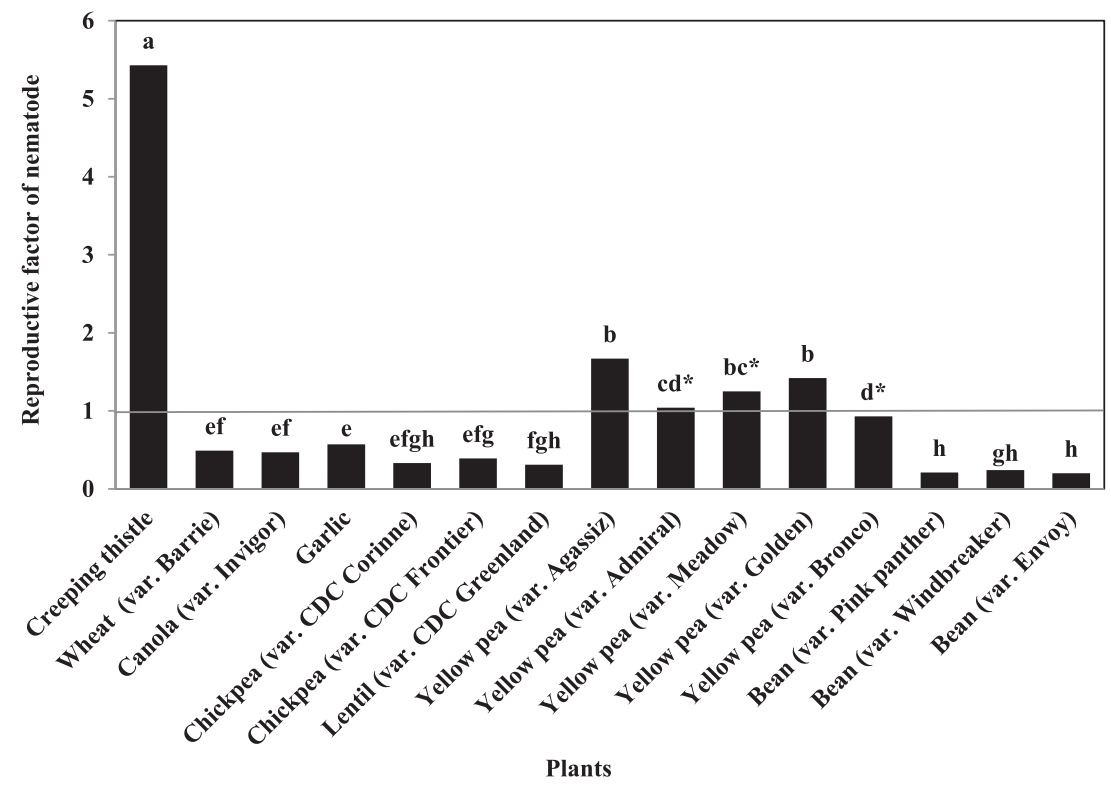

Fig. 1. Reproductive factor $\left(\mathrm{R}_{\mathrm{f}}\right)$ values (final density/initial density ratio) of Ditylenchus weischeri on pulse and non-pulse crops and creeping thistle grown in pots inoculated with an initial density of 100 fourth-stage juveniles/plant in host preference study. Values are the mean of two trials, with nine pots per trial $(n=18)$. Mean values with same letter are not significantly different according to Tukey's honestly significant difference test $(P=0.05)$. Asterisks indicate $\mathrm{R}_{\mathrm{f}}$ values are not different from 1 using the least-squares means $t$ test. 
However, the $\mathrm{R}_{\mathrm{f}}$ value on Kabuli chickpea was not statistically different from 1. Although $D$. dipsaci $\mathrm{R}_{\mathrm{f}}$ was lower than 1 in Greenland large green seed lentil $\left(R_{f}=0.92\right)$ and creeping thistle $\left(R_{f}=0.93\right)$, the $R_{f}$ on these crops did not differ significantly from 1 . The results showed that D. dipsaci failed to survive and reproduce in spring wheat and canola having $\mathrm{R}_{\mathrm{f}}$ values of 0.17 and 0.18 , respectively.

D. dipsaci reduced the biomass of four yellow pea (Admiral, Meadow, Golden, and Bronco) and two common bean (Windbreaker and Envoy) varieties compared with the corresponding noninoculated controls (Table 1). No reduction in the aboveground biomass of spring wheat, canola, lentil, or chickpea was observed, indicating that $D$. dipsaci was not able to affect plant performance in the current study. With regard to garlic, aboveground biomass weight was not reduced despite D. dipsaci reproducing well on the plant (Table 1). In the current study, different life stages of $D$. dipsaci stained with acid fuchsin were observed in the stem of garlic (not shown). The nematode reproduced and completed its life cycle successfully on garlic.
Seedborne transmission studies on $D$. weischeri and $D$. dipsaci. $D$. weischeri individuals were recovered from the stems (both bottom and top half), leaves, and roots of yellow pea. Densities of $D$. weischeri were significantly $(P<0.001)$ greater in stem than leaves, with only a few juveniles recovered from the roots of yellow pea (Table 2 ). D. weischeri failed to establish in seed pods and seed of Agassiz yellow pea when the plant was inoculated with 1,000 nematodes (Table 2), indicating that the nematode is not a seedborne parasite of yellow pea. Stems of creeping thistle supported the highest number of $D$. weischeri (Table 2). Juveniles and adults were also recovered from the roots, leaves, and flower heads of creeping thistle. There was a significant difference between the number of nematode individuals in stem and leaves of creeping thistle $(P<0.001$; Table 2). D. weischeri was also recovered from flower heads and seed of creeping thistle. D. weischeri parasitism on creeping thistle resulted in slight yellowing of leaves as well as swelling, twisting, and malformation of the stems and leaves (not shown). Occasionally,

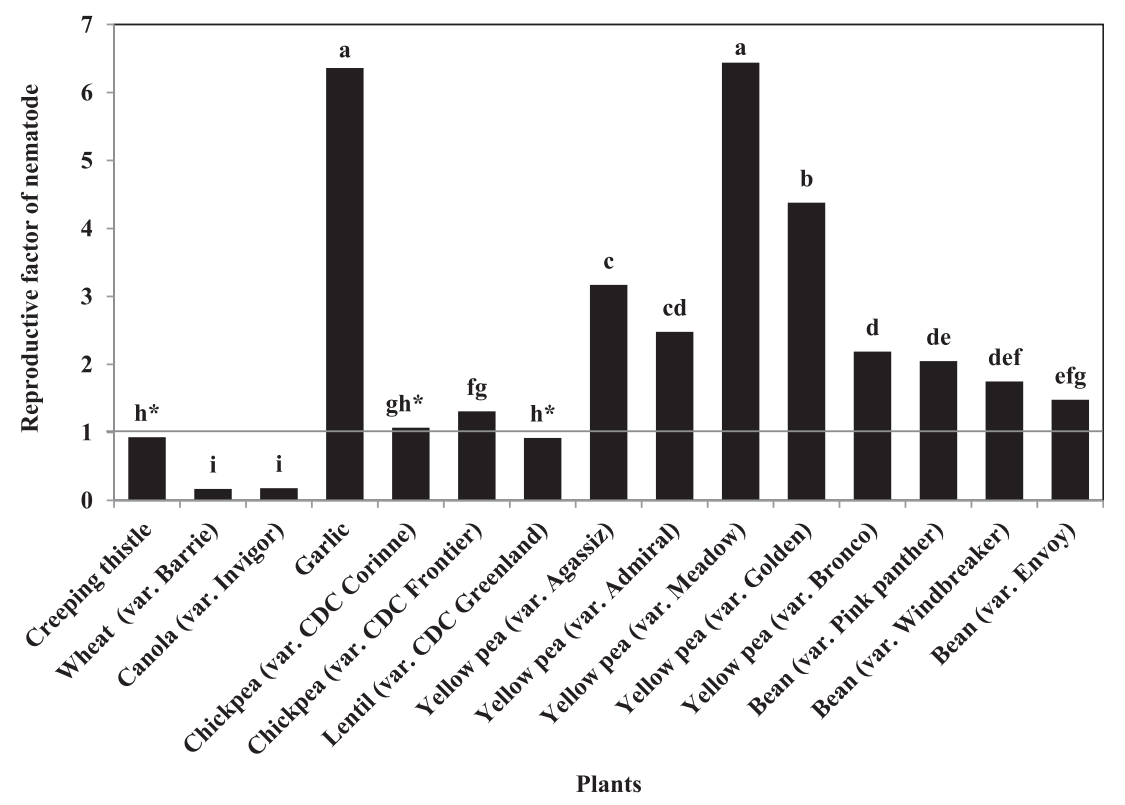

Fig. 2. Reproductive factor $\left(\mathrm{R}_{\mathrm{f}}\right)$ values (final density/initial density ratio) of Ditylenchus dipsaci on pulse and non-pulse crops and creeping thistle grown in pots inoculated with an initial density of 100 fourth-stage juveniles/plant in host preference study. Values are the mean of two repeat trials, with nine replicates per trial $(n=18)$. Mean values with same letter are not significantly different according to Tukey's honestly significant difference test $(P=0.05)$. Asterisks indicate $\mathrm{R}_{\mathrm{f}}$ values are not different from 1 using the least-squares means $t$ test.

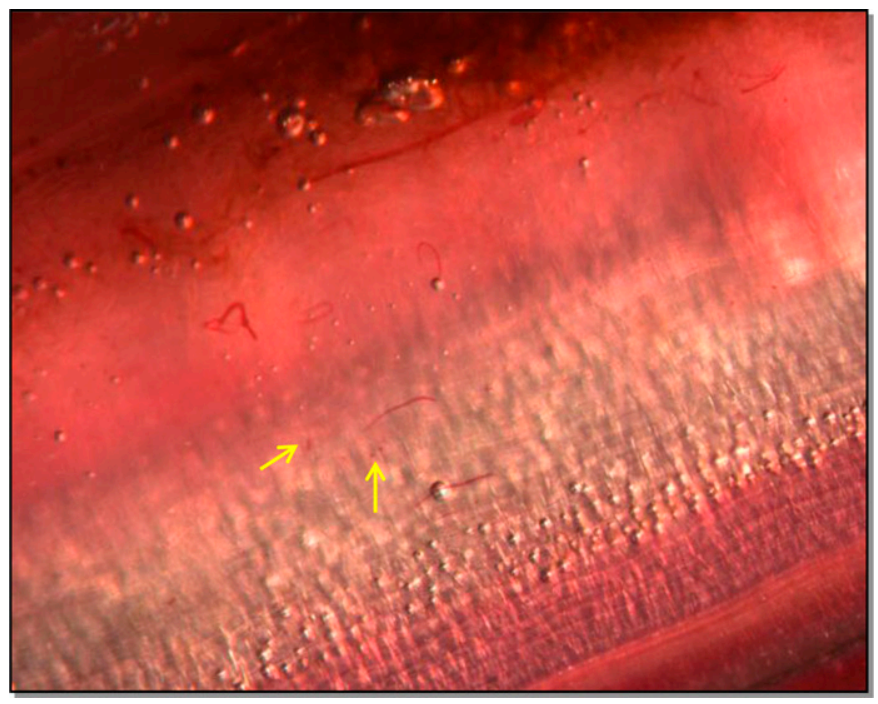

Fig. 3. Eggs (arrows) and different life stages of Ditylenchus weischeri in creeping thistle stem stained with acid fuchsin in host preference study. 
some necrotic lesions were seen on the stem of a few plants tested, with many nematode juveniles recovered from these lesions when cut and soaked in tap water.

$D$. dipsaci was recovered from throughout yellow pea tissues. Stems of yellow pea supported the highest number of the nematode (Table 2). There were significant differences in the number of the nematode between roots, stems, and leaves $(P<0.001)$. More $D$. dipsaci were recovered from the bottom portion of the stem compared with the top half of the stem and leaves (Table 2). A few nematodes were recovered from roots of yellow pea. D. dipsaci was recovered from seed pods and seed (Table 2). Very few D. dipsaci were recovered from the germ portion ( $7 \pm 1.1$ standard deviation) and storage cotyledons $(11 \pm 0.9)$ of yellow pea seed. With regard to creeping thistle, no $D$. dipsaci individual was recovered from the seed of the plant; however, a few nematodes were observed in the flower heads of creeping thistle (Table 2). In the present study, pea plants infested with $D$. dipsaci showed discoloration and deformation of leaf surfaces and margins as well as swelling of the stems and nodes (not shown).

\section{Discussion}

We report the first detailed examination of the host preference for the recently described stem nematode of creeping thistle, $D$. weischeri. These results provide further evidence for species distinction of $D$. weischeri from $D$. dipsaci based on very differing host preferences. This study confirmed that $D$. weischeri is capable of parasitizing creeping thistle, which was expected, considering that the test population used in the current study was obtained from naturally infested creeping thistle in Saskatchewan and Manitoba (Tenuta et al. 2014). Limited host preference screening of $D$. weischeri has previously been done. Chizhov et al. (2010) reported that the nematode was not able to parasitize another member of the Allium genus, onion. They also reported that the nematode did not reproduce on garden strawberry. Recently, the result of a host-suitability test showed that $D$. oncogene, a new stem nematode parasitizing sow thistle, does not infest broad bean (Vovlas et al. 2015). Based on the $R_{f}$ values in our greenhouse study, two of five yellow pea varieties examined were very weak hosts for $D$. weischeri. Also, the range of nematode reproduction was narrow among the varieties of yellow pea tested. Yellow pea is clearly not a preferred host and it seems that the nematode is capable of surviving on yellow pea and poorly reproducing on some varieties. There are no reports of $D$. weischeri or any other nematodes damaging to yellow pea in the Canadian Prairies. This seems to be in agreement with the results of the current study showing no reduction in biomass, no symptoms, and poor reproductive success on yellow pea varieties. However, further examination of $D$. weischeri development on yellow pea is required.

The seedborne transmission studies showed that $D$. weischeri was unable to infest seed pod and seed of yellow pea, indicating that the nematode is not likely be dispersed through movement of harvested pea grain clean of creeping thistle seed. In contrast, $D$. weischeri was a seedborne pest of creeping thistle, confirming previous observation (Tenuta et al. 2014). D. weischeri was able to develop and increase in density in creeping thistle, causing swelling and malformation on the plant. Extensive stem swelling or galls on naturally infected creeping thistle by $D$. weischeri have been observed in Russia (Chizhov et al. 2010) and in Saskatchewan and Manitoba (our personal observations). We observed no symptom of $D$. weischeri injury on yellow pea in our seedborne transmission study. This suggests that symptoms failed to become apparent due to very low development and reproduction of $D$. weischeri within the plant foliar tissue. However, lack of symptoms on yellow pea does not necessarily mean that nematode penetration and reproduction into plant tissues failed. Whitehead et al. (1987) observed plants such as onion, bean, potato, and alfalfa that were symptomless, though colonized by $D$. dipsaci.

The current study also reports the first detailed examination of host preference of the main crops grown on the Canadian Prairies for D. dipsaci. Our host preference study confirmed that $D$. dipsaci has an extremely wide host range, causing severe growth and yield reduction in many different plant species. Sturhan and Brzeski (1991) revealed the presence of several races of $D$. dipsaci which were distinguished on the basis of host response and parasite reproduction in a group of differential host plant tests. Some of these populations were later described as different Ditylenchus spp. based on molecular phylogenetic analyses. For example, a large-bodied stem and bulb nematode known as the giant race of $D$. dipsaci infecting broad bean was described as a new species, D. gigas (Vovlas et al. 2011).

In the present study, D. dipsaci was confirmed to strongly parasitize garlic, with a relatively very high $\mathrm{R}_{\mathrm{f}}$ value. This nematode has recently been reported to infest garlic fields in Québec, Ontario, and the northeastern United States (Fushtey and Kelly 1975; Testen et al. 2014; Yu et al. 2010) and, more recently, Manitoba from seed pieces imported from Ontario (Hajihassani and Tenuta 2016). D. dipsaci has also been reported in some alfalfa fields in British Columbia (Vrain and Lalik 1983). Our results revealed that all pulse crops tested can serve as hosts for $D$. dipsaci. In particular, yellow pea was an excellent host for $D$. dipsaci. These results agree with other reports of yellow pea being a good host for D. dipsaci (Aftalion and Cohn 1990; Janssen 1994; Mcburney 1981). Additionally, our results indicate the great potential for $D$. dipsaci to parasitize yellow pea and that the response of different varieties of yellow pea to this nematode species seems to be variable in terms of susceptibility, suggesting that there are significant differences in the ability of the parasite to establish and reproduce in the plant tissues of yellow pea varieties. Thus, there is potential for concern for $D$. dipsaci to move from garlic fields to pulse crops, especially yellow pea and dry bean. The likely invasion of the stem nematodes would favor the mild and moist conditions on the Canadian Prairies. Fortunately, except for a few market garden fields under cultivation with garlic in Alberta, Manitoba, and Saskatchewan, commercial production of garlic is limited on the Prairies. Nevertheless, in the future, growers should avoid the possibility of yellow pea and garlic being grown near each other.

The results from the seedborne transmission studies demonstrate that $D$. dipsaci is a seedborne parasite of yellow pea, indicating the ability of the nematode to be transmitted in harvested grain. D. dip$s a c i$ has been reported to be a seedborne nematode of many plant species, including broad bean and pea (Green and Sime 1979; Hooper 1972). Therefore, surveillance for the nematode in pea and bean fields as well as outreach to garlic and pulse growers to prevent dispersal of $D$. dipsaci are recommended. We found that the amount of disease development and severity was closely related to the number of $D$. dipsaci juveniles infesting the plant. Production of symptoms due to nematode injury varied due to environmental conditions and also structures of the plant foliage (French and John 1971). Typical symptoms induced by $D$. dipsaci in legume crops such as pea or bean

Table 2. Recovery of Ditylenchus weischeri and D. dipsaci from yellow pea (var. Agassiz) and creeping thistle in seed transmission studies

\begin{tabular}{lcc}
\hline & \multicolumn{2}{c}{ Recovered nematode numbers } \\
\cline { 2 - 3 } Plant parts & D. weischeri & D. dipsaci \\
\hline Yellow pea & $16 \mathrm{~d}$ & \\
Roots & $544 \mathrm{a}$ & $\mathrm{c}$ \\
Stems (bottom half) & $269 \mathrm{~b}$ & $981 \mathrm{a}$ \\
Stems (top half) & $173 \mathrm{c}$ & $476 \mathrm{~b}$ \\
Leaves & $0.0 \mathrm{e}$ & $232 \mathrm{~b}$ \\
Pods & $0.0 \mathrm{e}$ & $20 \mathrm{c}$ \\
Seed & 1,002 & $18 \mathrm{c}$ \\
Total & & 1,767 \\
Creeping thistle & $53 \mathrm{e}$ & \\
Root & $1,854 \mathrm{a}$ & $24 \mathrm{c}$ \\
Stem (bottom half) & $1,263 \mathrm{~b}$ & $367 \mathrm{a}$ \\
Stem (top half) & $516 \mathrm{c}$ & $261 \mathrm{ab}$ \\
Leave & $383 \mathrm{~cd}$ & $171 \mathrm{~b}$ \\
Flower head & $284 \mathrm{~d}$ & $7 \mathrm{c}$ \\
Seed & 4,353 & $0.0 \mathrm{~d}$ \\
Total & & 830 \\
\hline
\end{tabular}

${ }_{\mathrm{z}}$ Values in each column for a plant and nematode species combination followed by the same letter are not different significantly according to Tukey's honestly significant difference test $(P=0.05)$ using log-transformed data. 
have been observed as distortion and swelling of stem tissues as well as discoloration and deformation of leaves. Similar symptoms on yellow pea due to $D$. dipsaci were seen in the present study. In heavy infestations, the nematode may reduce seed viability and cause malformation and blackening of the seed coat and embryo (Bridge and Starr 2007; Mcburney 1981; OEPP/EPPO 2008; Stoddard et al. 2010).

In conclusion, the current study provides further evidence for species differentiation of the recently described $D$. weischeri from $D$. dipsaci. The former is a specific parasite of creeping thistle and not the major pulse crops, as well as wheat and canola grown on the Canadian Prairies. However, further examination of $D$. weischeri is warranted, considering the results shown here indicating that the nematode survived or slightly reproduced depending on yellow pea variety. $D$. dipsaci was confirmed a parasite of varieties of yellow pea and bean grown on the Canadian Prairies. In regard to D. dipsaci, it is important that the recent spread of the nematode to Manitoba garlic fields because of seed pieces imported from Ontario (Hajihassani and Tenuta 2016) be kept in check to prevent distribution to field pea.

\section{Acknowledgments}

This study was funded by the Alberta Pulse Growers, Manitoba Pulse and Soybean Growers, Saskatchewan Pulse Growers, and Agriculture and Agri-Food Canada Growing Forward II program. We thank B. Vandenberg, T. Warkentin, R. Conner, and B. Barlow for supplying seed; M. Celetti for providing garlic bulbs infested with $D$. dipsaci; M. Madani for assistance with nematode identification; and other members of the Soil Ecology Laboratory at the University of Manitoba for their technical assistance in this study.

\section{Literature Cited}

Aftalion, B., and Cohn, E. 1990. Characterization of two races of the stem and bulb nematode (Ditylenchus dipsaci) in Israel. Phytoparasitica 18:229-232.

Bridge, J., and Starr, J. L. 2007. Plant Nematodes of Agricultural Importance, a Colour Handbook. Manson Publishing Ltd., Tylor and Francis Group, Boca Raton, FL.

CABI. 2015. Ditylenchus dipsaci. Invasive Species Compendium: Datasheets, maps, images, abstracts and full text on invasive species of the world. Online publication. http://www.cabi.org/isc/datasheet/19287

Chizhov, V. N., Borisov, B. A., and Subbotin, S. A. 2010. A new stem nematode, Ditylenchus weischeri sp. n. (Nematoda: Tylenchida), a parasite of Cirsium arvense (L.) Scop. in the Central Region of the Non-Chernozem Zone of Russia. Russ. J. Nematol. 18:95-102.

Forge, T. A., Zasada, I. A., Pinkerton, J., and Koch, C. A. 2012. Host status and damage potential of Paratrichodorus renifer and Pratylenchus penetrans (Nematoda) to blueberry (Vaccinium spp.). Can. J. Plant Pathol. 34:277-282.

French, N., and John, M. E. 1971. Observations on the biology and control of stem eelworm (Ditylenchm dipsaci (Kühn) Filipjev) on hydrangea (Hydrangea macrophylla Ser.). Plant Pathol. 20:177-183.

Fushtey, S. G., and Kelly, C. B. 1975. A new record of stem and bulb nematode in Ontario. Can. Plant Dis. Surv. 55:27-28.

Green, C. D., and Sime, S. 1979. The dispersal of Ditylenchus dipsaci with vegetable seeds. Ann. Appl. Biol. 92:263-270.

Hajihassani, A., and Tenuta, M. 2016 First report of stem and bulb nematode (Ditylenchus dipsaci) on garlic in southern Manitoba, Canada. Can. Plant Dis. Surv. Vol. 96 (in press).

Hawn, E. J. 1963. Transmission of bacterial wilt of alfalfa by Ditylenchus dipsaci (Kühn). Nematologica 9:65-68.

Hooper, D. J. 1972. Ditylenchus dipsaci. In: CIH Descriptions of Plant Parasitic Nematodes, Set 1, No. 14. S. Willmott, ed. Commonwealth Institute of Helminthology, St. Albans, England.

Inomoto, M. M., and Asmus, G. L. 2010. Host status of graminaceous cover crops for Pratylenchus brachyurus. Plant Dis. 94:1022-1025.

Janssen, G. J. W. 1994. The relevance of races in Ditylenchus dipsaci (Kühn) Filipjev, the stem nematode. Fundam. Appl. Nematol. 17:469-473.
MacGuidwin, A. E., Wixted, D. J., and Hudelson, B. D. 1992. Aboveground infection of snap bean by Ditylenchus destructor, the potato rots nematode. Plant Dis. 76:1097-1102.

Madani, M., Tenuta, M., Chizhov, V. N., and Subbotin, S. A. 2015. Diagnostics of stem and bulb nematodes Ditylenchus weischeri and D. dipsaci (Nematoda: Anguinidae) using PCR with species specific primers. Can. J. Plant Pathol. 37:212-220.

Mcburney, T. 1981. Field assessment of stem nematode Ditylenchus dipsaci from visual symptoms in peas. Nematologica 27:115-117.

Mountain, W. B. 1957. Outbreak of the bulb and stem nematode in Ontario. Can. Plant Dis. Surv. 37:62-63.

OEPP/EPPO. 2008. Ditylenchus destructor and Ditylenchus dipsaci. OEPP/EPPO Bull. 38:363-373.

Plowright, R., Caubel, G., and Mizen, K. A. 2002. Ditylenchus species. Pages 107-139 in: Plant Resistance to Parasitic Nematodes. J. L. Starr, R. Cook, and J. Bridge, eds. CAB International, Wallingford, UK.

Saxton, A. M. 1998. A macro for converting mean separation output to letter groupings in Proc Mixed. Pages 1243-1246 in: Proc. 23rd SAS Users Group Int. SAS Institute, Cary, NC.

Sikora, R. A., and Greco, N. 1990. Nematode parasites of food legumes. Pages 197-198 in: Plant Parasitic Nematodes in Subtropical and Tropical Agriculture, 1st ed. M. Luc, R. A. Sikora, and J. Bridge, eds. CAB International, Wallingford, UK

Stoddard, F. L., Nicholas, A. H., Rubiales, D., Thomas, J., and VillegasFernández, A. M. 2010. Integrated pest management in faba bean. Field Crops Res. 115:308-318.

Sturhan, D., and Brzeski, M. W. 1991. Stem and bulb nematodes, Ditylenchus spp. Pages 423-464 in: Manual of Agricultural Nematology. W. R. Nickle, ed. Marcel Dekker Inc., New York.

Tenuta, M., Madani, M., Briar, S. H., Molina, O., Gulden, R. H., and Subbotin, S. A. 2014. Occurrence of Ditylenchus weischeri and not D. dipsaci in field pea harvest samples and Cirsium arvense in the Canadian Prairies. J. Nematol. 46:376-384.

Testen, A. L., Walsh, E. K., Taylor, C. G., Miller, S. A., and Lopez-Nicora, H. D. 2014. First report of Bloat nematode (Ditylenchus dipsaci) infecting garlic in Ohio. Plant Dis. 98:859.

Vanstone, V. A., and Russ, M. H. 2001. Ability of weeds to host the root lesion nematodes, Pratylenchus neglectus and P. thornei, I. Grass weeds. Australas. Plant Pathol. 30:245-250.

Vovlas, N., Troccoli, A., Palomares-Rius, J. E., De Luca, F., CantalapiedraNavarrete, C., Liébanasc, G., Landa, B. B., Subbotin, S. A., and Castillo, P. 2015. A new stem nematode, Ditylenchus oncogenus n. sp. (Nematoda: Tylenchida), parasitizing sowthistle from Adriatic coast dunes in southern Italy. J. Helminthol. 3:1-14.

Vovlas, N., Troccoli, A., Palomares-Rius, J. E., De Luca, F., Liébanasc, G., Landa, B. B., Subbotin, S. A., and Castillo, P. 2011. Ditylenchus gigas n. sp. parasitizing broad bean: A new stem nematode singled out from the Ditylenchus dipsaci species complex using a polyphasic approach with molecular phylogeny. Plant Pathol. 60:762-775.

Vrain, T. C., and Lalik, B. 1983. Distribution and pathogenicity of the alfalfa stem nematode, Ditylenchus dipsaci in British Columbia. Plant Dis. 67:300-302.

Watson, A. K., and Shorthouse, J. D. 1979. Gall formation on Cirsium arvense by Ditylenchus dipsaci. J. Nematol. 11:16-22.

Whitehead, A. G., Fraser, J. E., and Nichols, A. J. F. 1987. Variation in the development of stem nematodes, Ditylenchus dipsaci, in susceptible and resistant crop plants. Ann. Appl. Biol. 111:373-383.

Whitehead, A. G., and Hemming, J. R. 1965. A comparison of some quantitative methods of extracting small vermiform nematodes from soil. Ann. Appl. Biol. 55:25-38.

Yu, Q., Ye, W., Badiss, A., and Sun, F. 2010. Description of Ditylenchus dipsaci (Kühn, 1857) Filipjev, 1936 (Nematoda: Anguinidae) infesting garlic in Ontario, Canada. Int. J. Nematol. 20:185-192.

Zhang, S. L., Liu, G. K., Janssen, T., Zhang, S. S., Xiao, S., Li, S. T., Couvreur, M., and Bert, W. 2014. A new stem nematode associated with peanut pod rot in China: Morphological and molecular characterization of Ditylenchus arachis n. sp. (Nematoda: Anguinidae). Plant Pathol. 63:1193-1206. 